\author{
Samanta Simioni \\ Christiane Ruffieux \\ Joerg Kleeberg \\ Laure Bruggimann \\ Jean-Marie Annoni \\ Myriam Schluep
}

\section{Preserved decision making ability in early multiple sclerosis}

Received: 30 November 2007

Received in revised form: 9 May 2008

Accepted: 5 June 2008

Published online: 13 November 2008

S. Simioni $\cdot$ J. Kleeberg, MD $\cdot$ L. Bruggimann

- J.-M. Annoni, MD · M. Schluep, MD (区)

Dept. of Neurology

Centre Hospitalier Universitaire Vaudois

(CHUV)

1011 Lausanne, Switzerland

Tel.: +41-21/314-1269

Fax: +41-21/314-3259

E-Mail: Myriam.Schluep@chuv.ch.

C. Ruffieux

Dept. of Social and Preventive Medicine

Centre Hospitalier Universitaire Vaudois (CHUV)

1011 Lausanne, Switzerland

J.-M. Annoni

Dept. of Neurology

Geneva University Hospital

1211 Geneva 14, Switzerland
Abstract Background The purpose of this study was to assess decision making in patients with multiple sclerosis (MS) at the earliest clinically detectable time point of the disease. Methods Patients with definite MS $(n=109)$ or with clinically isolated syndrome (CIS, $\mathrm{n}=56$ ), a disease duration of 3 months to 5 years, and no or only minor neurological impairment (Expanded Disability Status Scale [EDSS] score 0-2.5) were compared to 50 healthy controls using the Iowa Gambling Task (IGT). Results The performance of definite MS, CIS patients, and controls was comparable for the two main outcomes of the IGT (learning index: $\mathrm{p}=0.7$; total score: $p=0.6)$. The IGT learning index was influenced by the educational level and the co-occurrence of minor depression. CIS and
MS patients developing a relapse during an observation period of 15 months dated from IGT testing demonstrated a lower learning index in the IGT than patients who had no exacerbation $(p=0.02)$. When controlling for age, gender and education, the difference between relapsing and non-relapsing patients was at the limit of significance $(\mathrm{p}=0.06)$. Conclusion Decision making in a task mimicking real life decisions is generally preserved in early MS patients as compared to controls. A possible consequence of MS relapsing activity in the impairment of decision making ability is also suspected in the early phase of MS.

Key words multiple sclerosis . Iowa Gambling Task $\cdot$ decision making $\cdot$ behavior $\cdot$ relapse

\section{Introduction}

Multiple sclerosis (MS) is a chronic inflammatory demyelinating disease of the central nervous system (CNS) which affects primarily the white matter. The extent of MS burden is reflected by the degree of impairment of neurological and cognitive functions and by emotional changes, although the influence of disease characteristics, such as duration, course, annual relapse rate, and physical disability, on cognitive and behavioral pro글 cesses is still a matter of debate $[1-2,14,23,34]$. In MS, magnetic resonance imaging (MRI) often detects wide- within the CNS. Besides, quantitative MRI, functional MRI or diffusion-weighted imaging techniques show abnormalities in apparently unaffected brain tissue [28, 38]. Such alterations in normal-appearing white and grey matter may provoke brain dysfunction and lead to measurable cognitive and behavioral changes.

The ability to make self-advantageous decisions represents an important factor for adequate social behavior in everyday life [19]. Decision making has been defined as the process through which a person forms preferences, selects and executes actions, and evaluates the outcome related to a selected choice [18]. The interplay between decision making and emotional processing has been studied in several neurological conditions using 
the Iowa Gambling Task (IGT) and skin response conductance (SCR) [7-9, 19]. According to Damasio's somatic marker hypothesis $[10,15]$, decision making is dependent on the emotional reactivity induced by specific environmental events, which provides a substrate for biasing decision by signals to a large subcortical frontal network including the amygdala and ventromedial prefrontal cortex. Given that MS is a disseminated process, we had previously hypothesized that it could modify decision making towards more risky choices by different types of functional frontal disconnection or by MS induced cortical atrophy. Using the IGT, we were able to demonstrate delayed learning in decision making in a group of patients with relapsing-remitting (RR) and secondary progressive (SP) MS [22]. This finding, which represented impaired use of previous outcome experiences in making appropriate new decisions, was associated with an inability to generate somatic markers of an emotional experience, as measured by the SCR. Recently, Nagy et al. [30] assessed decision making using the IGT in a small group of RRMS patients with mild disability (mean Kurtzke Expanded Disability Status Scale [EDSS] 1.7) [24] and a short disease duration (mean 3.1 years). Their results confirmed our findings that MS patients show altered decision making ability, and suggested that this was the consequence of impaired learning ability and of a greater sensitivity to recent outcomes, independently of the gains or losses experienced in the IGT.

The purpose of the present study was to provide further information on decision making ability in MS patients with no definite neurological handicap, and who were active in everyday life in the professional, familial, and social fields. By including patients with definite MS and with clinically isolated syndrome [CIS], with a short disease duration and minor neurological disability, we aimed to assess decision making abilities in MS patients standing at the earliest accessible time point, which is represented by the first clinical manifestation of MS. For this purpose, we used the diagnostic criteria of McDonald et al. [27] and revised by Polman et al. [31], which allow the detection of such patients by placing considerable emphasis on MRI-derived information. The identification of clinically silent lesions at least three months after a first CNS demyelinating episode allows an early diagnosis of definite MS. Thus, increasing the detection of impairments in the early stage of MS is an important issue that can have an effect on the therapeutic attitude by identifying MS patients at risk of developing a more severe disease with a sustained handicap.

We postulated that (1) early MS patients without disability may make more risky choices in the IGT than healthy subjects, (2) MS patients with a higher disease activity, defined by the occurrence of a relapse during an observation period of 15 months after performing the IGT, may be impaired earlier in their ability of decision making than stable patients (i.e., without relapses), (3) "risk-taking" MS patients may finally present different behavioral characteristics, a lower quality of life (QoL), or a higher perceived handicap than "non-risk-taking" MS patients, defined according to their IGT performance.

\section{Patients and methods}

\section{Subjects}

One hundred and sixty-five early MS patients (117 women and 48 men) aged 18 to 65 years (mean age 35.4 years) were included in this transversal study. Only patients with a relapsing course, no or only minor neurological impairment (EDSS score $0-2.5$ ), and with a disease duration of three months to five years were considered. Sixtyeight patients received interferon- $\beta 1 \mathrm{a}$ or $1 \mathrm{~b}, 19$ selective serotonin reuptake inhibitors for depressive symptoms, and five amantadine as a symptomatic treatment for fatigue. Patients were assessed once, at inclusion, for decision making, general cognitive functioning and behavior. CIS patients were tested at least three months after disease onset in order to apply McDonald criteria, while definite MS patients were tested at least six weeks after an exacerbation or corticosteroid treatment to avoid transient deficits or dysregulations.

Subsequently, all patients were followed up neurologically for 15 months, and relapses systematically recorded and formally evaluated. This objective assessment is crucial, since the relapse rate during the first and second years of MS is considered to be an indicator of clinical outcome, given the risk to develop a sustained disability later on [17].

At inclusion, based on McDonald criteria [27,31], 109 patients had definite MS (clinically definite MS or MS confirmed by dissemination in time and space using MRI) and 56 had CIS. During the observation period of 15 months after inclusion, 53 patients had a relapse. Of these, 17 were CIS at inclusion and thus evolved to definite MS ; the other 36 patients had already definite MS.

The control group consisted of 50 healthy volunteers ( 35 women and 15 men) aged 18 to 60 years (mean age 32.2), who were invited to participate as controls for the IGT. These normal subjects did not participate to either the cognitive tasks or the behavioral questionnaires. None of the patients or controls had a history of alcohol or drug abuse, major psychiatric disorder (major depression, psychosis, untreated bipolar disorders), head trauma, other neurological disorder, or systemic illness.

The study was approved by the local university Ethics Committee according to the Declaration of Helsinki (1961), and all patients and controls signed an informed consent form before participating in this study.

\section{Procedure}

Cognitive deficits were screened in the MS group at study entry using tests evaluating two of the main impaired domains in MS, namely long-term memory and executive functions $[11,32]$. The tests used were the Rey's Auditory Verbal Learning Test [5], the six subtests from the Behavioral Assessment of the Dysexecutive Syndrome [40], and the Trail Making Test [33]. The presence of a cognitive impairment in a patient was defined by a performance two standard deviations (SD) below the given mean for a test. Impaired patients were those who failed in at least one neuropsychological measure [37].

In addition, questionnaires assessing behavioral symptoms (Dysexecutive Questionnaire [DEX], Iowa Scale of Personality Change [ISPC]) [6, 40], fatigue (Fatigue Assessment Instrument [FAI]) [35], mood disorders (Hospital Anxiety and Depression scale [HAD] [42], and a semi-structured psychiatric interview using DSM-IV criteria), handicap (London Handicap Scale [LHS]) [21], and QoL (SEP-59) 
[39] were also completed by the patient or a relative, in order to control for a possible effect of behavioral and functional factors on decision making [16].

Decision making was assessed in MS patients and controls using a computerized version of the IGT, administered as described by Bechara et al. [7]. Subjects were told that the aim of the game was to win as much money as possible. Four decks (A, B, C, and D) were presented on a computer screen and they had to select a card from any of the decks using the mouse. After picking a card, the gain or loss of money was displayed on the computer screen, together with a corresponding happy or sad face. The game consisted of 100 trials. Decks $A$ and $B$ were associated with high immediate wins, but even higher future losses, ending in a long-term loss (disadvantageous decks), whereas decks $C$ and $D$ were associated with low immediate wins, but even lower future losses, resulting in a long-term gain (advantageous decks).

For data analysis, the number of cards picked from decks A and B or from $\mathrm{C}$ and $\mathrm{D}$ were summed separately. Skill in decision making was assessed by means of a total score defined as the difference between the number of choices from advantageous or disadvantageous decks $([(C+D)-(A+B)])$. This score ranged from -100 (choices from disadvantageous decks only) to +100 (choices from advantageous decks only). A 5-block index representing the difference between the number of advantageous and disadvantageous choices per block of 20 cards was defined (B1, B2, B3, B4, B5) and rescaled to vary between -1 and +1 . A learning index aimed at measuring the ability to evolve in the process of decision making was defined as the difference between the averaged last three block indexes and first two block indexes (learning index $=[(\mathrm{B} 3+\mathrm{B} 4+\mathrm{B} 5) / 3]-[(\mathrm{B} 1+\mathrm{B} 2) / 2])$.

\section{Statistical analysis}

Statistical analyses were conducted using a STATA software package (Version 9.0). The distributions of some of the scores and indexes were not quite normal. We thus used systematically nonparametric tests in univariate analysis and robust estimating procedures for multivariable analysis.

1. We compared the definite MS, CIS and control groups for demographic variables by means of a 3-way Kruskall-Wallis test (for age) and of chi2 (for gender and education). We then compared the definite MS and CIS groups for clinical variables by means of a Wilcoxon test (for disease duration and EDSS score) and of chi2 (for immunomodulatory and antidepressive treatment, diagnosis of minor depression, and occurrence of a relapse). The performances in neuropsychological and behavioral assessments were compared between definite MS and CIS patients by means of chi2 (for the proportion of cognitive deficits, depressed and anxious symptoms, dysexecutive behaviors and fatigue) and Wilcoxon tests (for behavioral changes, and scores of handicap and QoL).

2. We compared the definite MS, CIS and control groups for the two main outcomes of the IGT (the total score and the learning index) by means of a 3-way Kruskall-Wallis test. We also compared patients who experienced a relapse during the 15-months follow-up and those who did not, globally and separately for definite MS and CIS using Wilcoxon tests.

3. Focusing then on patients only (definite MS and CIS), we investigated if associations could be found between the learning index and the covariates. We used Spearman correlations (for age, disease duration, EDSS score, behavioral changes, and scores of handicap and QoL) or Wilcoxon tests (for gender, education, immunomodulatory treatment, diagnosis of minor depression, use of antidepressants, proportion of cognitive deficits, depressed and anxious symptoms, dysexecutive behaviors and fatigue).

4. Comparison between patients who experienced a relapse during the 15-months follow-up and those who did not was tested controlling for potential confounders and stratifying for phenotype. For this test, a multivariable robust linear regression model was built for the learning index as a dependent variable, and the occurrence of a relapse, the phenotype at baseline, age, gender, education, occurrence of immunomodulatory treatment and diagnosis of minor depression as independent variables. All these covariates were entered in the model. A backward procedure was used to obtain the final model. The criterion used to keep a covariate in the final model was a p-value $<0.10$. The residuals from the final model were plotted against predicted values and against each regressor to check the validity of the model (diagnostic plots).

5. We also repeated the points 3 and 4 for the IGT total score.

\section{Results}

Definite MS patients, CIS patients and controls were comparable in terms of gender (respectively, $67 \%, 79 \%$ and $70 \%$ of women; $\mathrm{p}=0.3$ ) and education (respectively, $86 \%, 87 \%$ and $84 \%$ had at least high-school education; $\mathrm{p}=0.4$ ) but not for age (respectively, 34 [SD 9.2], 37.9 [SD 8.3] and 32.2 [SD 11.1]; $\mathrm{p}<0.001$ ). Clinical and neuropsychological characteristics of MS and CIS patients (disease duration, EDSS score, occurrence of a relapse, use of immunomodulators, diagnosis of minor depression, use of antidepressants, prevalence of cognitive deficits) are given in Table 1, and the behavioral, handi-
Table 1 Clinical variables for definite MS and CIS patients at inclusion, concomitantly to the IGT testing

\begin{tabular}{lclc}
\hline & $\begin{array}{l}\text { Definite MS } \\
(\mathrm{n}=109)\end{array}$ & $\begin{array}{l}\text { CIS } \\
(\mathrm{n}=56)\end{array}$ & p-value \\
\hline Disease duration (years) (mean [SD]) & $2.8(1.9)$ & $1.4(1.3)$ & 0.0001 \\
EDSS score (mean [SD]) & $1.82(0.4)$ & $1.66(0.4)$ & 0.01 \\
Patients relapsing after inclusion (\%) & 33 & 30 & 0.7 \\
Immunomodulators (\% of patients) & 54 & $16^{* *}$ & $<0.0001$ \\
Diagnosis of minor depression (\% of patients) & 8 & 11 & 0.6 \\
Antidepressants (\% of patients) & 10 & 16 & 0.3 \\
Cognitive impairment (\% of patients) & 34 & 25 & 0.2 \\
\hline
\end{tabular}

* Antidepressants were used for minor depression according to the DSM IV criteria and mood swing since major depression was an exclusion criterion

** Nine CIS patients fulfilling MCDonald criteria for a dissemination in space of the lesions were receiving low doses interferon-beta 1a (Rebif ${ }^{\circledR} 1$ x $22 \mu \mathrm{g}$ weekly), which was at that time registered in Switzerland for the treatment of possible MS 
cap, and QoL scores are presented in Table 2. Based on published normative data $[5,33,40], 51$ patients $(31 \%)$ of the complete sample (definite MS and CIS) displayed an impaired performance in the neuropsychological assessment.

Comparing definite MS and CIS patients, disease duration, the percentage of patients treated with immunomodulators, and the number of behavioral modifications in the ISPC were the only clinical variables showing a statistical difference. The prevalence of cognitive deficits was comparable between definite MS and CIS patients, as well as between relapsing (34\%) and stable $(29 \%)$ patients $(\mathrm{p}=0.6)$. More specifically, verbal learning abilities (RAVLT) were similar $(\mathrm{p}=0.6)$, as well as performances of attention/processing speed (TMT part $A: p=0.6$; TMT part $B: p=0.8$ ). However, subgroups differed according to executive scores which were higher in stable than in relapsing patients $(\mathrm{p}=0.02)$.

\section{Decision making ability in early MS patients (definite MS and CIS), and controls}

The $[(\mathrm{C}+\mathrm{D})-(\mathrm{A}+\mathrm{B})]$ total score was $7.9(\mathrm{SD} 33.7)$ in the control group and 4.0 (SD 28.4) in the patients' group but this difference was not statistically significant $(p=0.4)$.The 5-block index increased over time in both groups, implying that subjects were able to recognize that decks $\mathrm{A}$ and $\mathrm{B}$ were disadvantageous. The mean of the first two block indexes was negative and comparable in controls and MS patients ( -0.06 [SD 0.27] and -0.09 [SD 0.21] respectively; $p=0.3$ ), indicating a higher number of disadvantageous choices in both groups. The mean over the last three blocks was greater for the con-

Table 2 Percentages of definite MS and CIS patients with pathological scores in the HAD, DEX, and FAl. Number of acquired behavioral traits and scores of handicap and QoL

\begin{tabular}{lllc}
\hline & $\begin{array}{l}\text { Definite MS } \\
(\mathrm{n}=109)\end{array}$ & $\begin{array}{l}\text { CIS } \\
(\mathrm{n}=56)\end{array}$ & p-value \\
\hline Behavior & & & \\
$\quad$ HAD-A $>8(\%)$ & 49 & 56 & 0.4 \\
HAD-D $>8(\%)$ & 20 & 15 & 0.4 \\
DEX patients $>38(\%)$ & 16 & 9 & 0.2 \\
DEX relatives $>24.5(\%)$ & 46 & 39 & 0.4 \\
FAl severity $>$ 4.26 (\%) & 57 & 50 & 0.4 \\
ISPC number of behavioral & $6.5(5.8)$ & $3.2(3.9)$ & $<0.001$ \\
$\quad$ modifications & & & \\
Handicap and QoL & & & \\
$\quad$ LHS & $9.0(3.3)$ & $8.2(2.9)$ & 0.5 \\
SEP-59 & $46.4(11.0)$ & $44.7(9.7)$ & 0.3 \\
\hline
\end{tabular}

HAD Hospital Anxiety and Depression scale; DEX Dysexecutive Questionnaire; FAI Fatigue Assessment Instrument; ISPC lowa Scale of Personality Change; LHS London Handicap Scale trol group than for MS patients (0.18 [SD 0.47] and 0.13 [SD 0.40], respectively) but the difference was not significant $(\mathrm{p}=0.4)$. Learning index was 0.24 (SD 0.44) in the control group and 0.21 (SD 0.38) in the MS group and the difference was not statistically significant $(\mathrm{p}=0.7)$.

\section{Decision making ability in definite MS patients, CIS patients and controls}

The $[(\mathrm{C}+\mathrm{D})-(\mathrm{A}+\mathrm{B})]$ total score was 7.9 (SD 33.7) in the control group, 4.1 (SD 29.7) in the definite MS group, and 3.9 (SD 29.5) in the CIS group. This difference between the three groups was not statistically significant $(\mathrm{p}=0.6)$. The learning index was 0.24 (SD 0.44) in the control group, 0.22 (SD 0.38) in the definite MS group and 0.19 (SD 0.37) in the CIS group. This difference between the three groups was also insignificant $(p=0.7)$ (Table 3 ). The 5-block index increased over time in all three groups $(\leq 1)$ and the learning index was significantly $>0$ according to the $95 \% \mathrm{CI}$, indicating that in average there was a trend toward a recognition of the decks $A$ and $B$ as disadvantageous by all patients and controls (definite MS: $95 \%$ CI [0.09-0.29]; CIS : $95 \%$ CI [0.15-0.30]; controls: $95 \% \mathrm{CI}[0.11-0.36])$.

\section{Decision making ability and MS clinical activity}

The $[(\mathrm{C}+\mathrm{D})-(\mathrm{A}+\mathrm{B})]$ total score was $-0.87(\mathrm{SD} 26.41)$ in the group composed of the $53 \mathrm{MS}$ patients who experienced a relapse during the 15 months following their inclusion and 6.36 (SD 29.22) in stable (i.e., no relapse) CIS and MS patients. This difference was not significant $(\mathrm{p}=0.1)$, but the learning index differed between the two groups $(0.12$ [SD 0.38 ] in relapsing patients vs. 0.26 [SD 0.37 ] in stable patients; $p=0.02$ ) (Table 3 ). Stratifying by the phenotype showed on the one hand that stable definite MS had nearly the same learning index than stable CIS and controls (respectively 0.27 [SD 0.38], 0.23 [SD 0.37 ] and 0.24 [SD 0.44$]$ ), and on the other hand that

Table $3[(C+D)-(A+B)]$ total score and learning index for the definite MS, CIS patients and controls, and in stable vs. relapsing patients

\begin{tabular}{lcl}
\hline & $\begin{array}{l}\text { Total score } \\
\text { (mean [SD]) }\end{array}$ & $\begin{array}{l}\text { Learning index } \\
\text { (mean [SD]) }\end{array}$ \\
\hline Definite MS $(n=109)$ & $4.1(28.1)$ & $0.2(0.4)$ \\
CIS $(n=56)$ & $3.9(29.5)$ & $0.2(0.4)$ \\
Controls $(n=50)$ & $7.9(33.6)$ & $0.2(0.4)$ \\
p-value & $\mathbf{0 . 6}$ & $\mathbf{0 . 6}$ \\
Stable patients $(n=112)$ & $6.4(29.2)$ & $0.3(0.4)$ \\
Relapsing patients $(n=53)$ & $-0.9(26.4)$ & $0.1(0.4)$ \\
p-value & $\mathbf{0 . 1}$ & $\mathbf{0 . 0 2}$ \\
\hline
\end{tabular}


Fig. 1 Evolution of the $[(C+D)-(A+B)]$ index per block of 20 cards (B1 to $B 5$ ) in controls, definite MS and CIS patients. For each boxplot, the middle horizontal line is the median, the bottom and top represent quartiles 1 and 3 , the upper and lower bars mark the last observation at a distance of less than 1.5 times the interquartile range from the edge of the box, and the diamonds represent all observations that are outside the bars
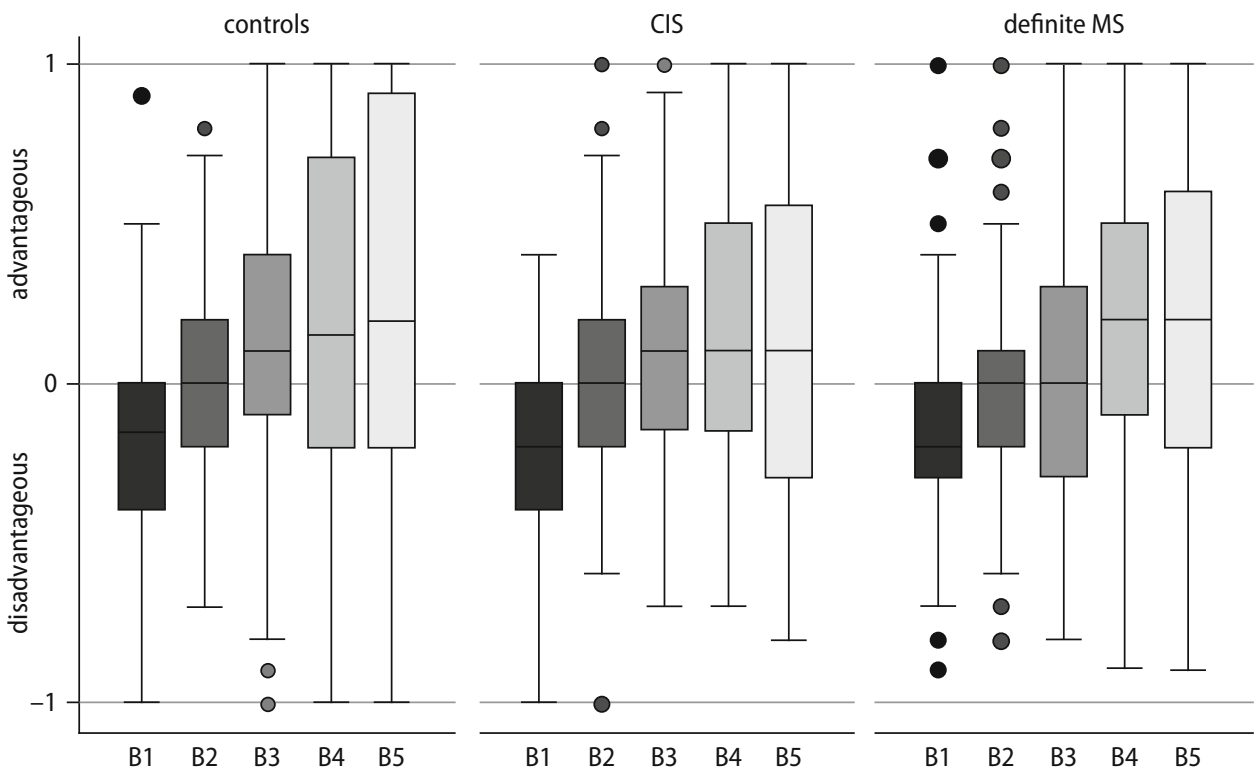

relapsing definite MS patients had almost the same learning index as relapsing CIS (respectively 0.13 [SD 0.39 ] and 0.10 [SD 0.35]). The learning index did not significantly differ between relapsing and stable patients, both in the definite MS $(p=0.1)$ and the CIS $(p=0.1)$ groups.

\section{Associations between decision making ability and the covariates in the patients' group}

Few variables were found to be associated with the learning index. In the whole early MS group (definite MS and CIS), women had a smaller learning index than men but the difference was not significant (0.19 [SD 0.35] for women vs. 0.27 [SD 0.44] for men; $p=0.1)$. Patients with a higher educational level ( $>12$ years of education or academic background) had a higher learning index ( 0.35 [SD 0.41]) than patients with a lower educational level $(0.17$ [(SD 0.36]) $(\mathrm{p}=0.006)$. A trend to an association was also found between the learning index and the presence of a minor depression according to the DSM IV criteria (0.06 [SD 0.31] for depressed patients and 0.23 [SD 0.38] for nondepressed patients; $\mathrm{p}=0.07$ ). When excluding patients treated with antidepressants from the IGT analysis, the learning index became similar between definite MS, CIS, and controls $(\mathrm{p}=0.4)$, as well as between relapsing and stable patients $(p=0.2)$. Finally, focusing on stable patients only, risky decision making in the IGT $([(\mathrm{C}+\mathrm{D})-(\mathrm{A}+\mathrm{B})]$ total score $>0)$ was associated with higher scores in the DEXp (25.3 [16.3] for risk takers vs. 16.7 [9.5] for no-risk takers; $p=0.01$ ) and DEXr (27.5 [11.9] vs. 21.2 [10], respectively; $p=0.01$ ), as well as with a slightly higher number of behavioral changes in the ISPC (6.8 [6.5] vs. 4.3 [4.3], respectively; $p=0.6)$. No association was found with cognitive impairment (34\% vs. $26 \%, \mathrm{p}=0.4)$.

\section{Multivariable model for the IGT learning index}

Potential confounders for the relation between the learning index and disease activity were selected a priori (see statistical analysis in the Methods section). In the final model, after adjustment for age, gender, and education, the estimated difference in the learning index between stable and relapsing patients was 0.12 , a value which is at the limit of significance $(p=0.06)$. Phenotype, presence of an immunomodulatory treatment and diagnosis of minor depression were not retained in the final model ( $p$-value $>0.1$ ). The diagnostic plots (as well as formal tests) showed that no interaction was necessary.

The same analytical frame was followed for the $[(C+D)-(A+B)]$ total score, and the results obtained were insignificant $(p=0.2)$.

\section{Discussion}

We assessed decision making ability in a large sample of definite MS and CIS patients standing in the early course of the disease, some of whom being at the earliest clinically detectable stage of MS [27,31]. Our main finding is that, in such an early MS population, the ability to learn to avoid disadvantageous decks in the IGT does not differ from that of controls and that, in contrast to more advanced MS [22], decision making seems to be preserved in the early stages of the disease. Our results differ from those of Nagy et al. [30] who found impaired decision making in MS patients with mild disability. 
However, they tested a slightly more advanced MS population (all their patients already had definite MS and disease duration was one year longer on average) and the presence of IGT difficulties in their study group might be related to the evolution of the MS process.

Indeed, Nagy et al. [30] hypothesized that decision making difficulties at an early stage of MS may reflect sub-clinical pathology. The observation that the development of a relapse within the 15 months following the test was, in some extent, related to the IGT performance after adjustment for demographic characteristics gives weight to their hypothesis. In fact, these relapsing patients demonstrated a lower learning index in the IGT in comparison to stable patients who switched more clearly from disadvantageous to advantageous decks during the task. The role of the activity itself, of changes in executive functions (measured by the BADS) and mood (as reflected by the use of antidepressants) is however difficult to disentangle.

The behavioral mechanisms by which difficulties in decision making occur in MS and more generally is still debated. According to Maia \& McLelland [26], consciously accessible knowledge may induce overt behavior and verbal reports, which influence directly decision making; the use of non-conscious somatic markers may not be necessary in that context. For Nagy etal. [30], poor decision making was rather the consequence of an impaired learning process across trials and of a greater sensitivity to recent outcomes, independently of gains or losses. Finally, we have previously suggested an impairment of emotional experience instead of cognitive changes as an inducing mechanism [22]. In the present work, IGT performances were associated with DEX scores in stable patients, giving weight to our previous hypothesis of a link between decision making and emotional behavior. Moreover, an interesting finding was that minor depression was one of the two covariates that significantly influenced the IGT results (the other one being education). The MS literature provides a couple of other studies showing that depressed MS patients performed significantly worse on executive types of cognitive tasks that could be construed as overlapping somewhat in the constructs measured by the IGT. Specifically, Arnett et al. reported lower performances in a depressed group of MS patients in comparison to nondepressed MS patients on a planning task [4], and showed the same pattern for a working memory task that is considered executive in nature [3]. Besides, Landro et al. [25] reported that depressive symptoms also accounted for slowed information processing speed in MS patients.
Impairment in decision making has generally been described in focal frontal lesions [9] but was also found in more diffuse neurological or psychiatric diseases, in which vulnerable widespread networks may be responsible for a decreased decision making efficacy $[29,36]$. This vulnerability in MS could be related to transient inflammation and/or to a more chronic demyelinating and degenerative process. MRI measurements of cerebral lesion load and inflammatory activity, which were not performed in the present evaluation, would provide interesting complementary data to analyze in future studies on decision making in MS more focalized on the understanding of underlying mechanisms.

The variability of the IGT responses obtained in the normal population may have been a limiting factor for detecting more significant differences between the groups we have tested. Indeed, variability in the IGT performances is a classical finding in healthy controls and inter-individual differences in brain mechanisms related to gender [12], age [20] or personality traits $[16,41]$ may possibly explain this phenomenon. However, the association between IGT performances and DEX scores in stable patients might also reflect such behavioral variability in the MS population. Such transversal study is obviously a first step, and decision making should be tested in follow-up analyses, with validated parallel version of IGT. We are currently preparing a longitudinal study in MS patients to evaluate associations between disease progression and modifications of performances in IGT.

In conclusion, the results obtained in a well defined population of early MS patients, some of whom were tested at the first detectable time point in their disease course, suggest that the ability of decision making is generally preserved in early MS but also argue for a possible association of MS activity with the impaired process of decision making. Further complementary analyses including MRI studies should be performed to give a more sensitive picture of the extent of the burden secondary to MS, and to confirm this observation.

\footnotetext{
Conflict of interest The authors declare no conflict of interest.

Acknowledgments The authors are grateful to Dr A. Bechara for providing a computerized version of the Iowa Gambling Task and to Ms C. Peter-Favre and A.-C. Juillerat for providing access to the ISPC French version. The authors thank Ms G. Le Goff (specialized MS nurse) for her contribution to the performance of the study. This work was supported by grants from the Swiss Society for Multiple Sclerosis and the Swiss National Science Foundation (3200BO-104051, to MS).
} 


\section{References}

1. Amato MP, Ponziani G, Pracucci G, Bracco L, Siracusa G, Amaducci L (1995) Cognitive impairment in earlyonset multiple sclerosis: pattern, predictors and impact on everyday life in a 4-year follow-up. Arch Neurol 52: 168-172

2. Amato MP, Ponziani G, Siracusa G, Sorbi S (2001) Cognitive dysfunction in early-onset multiple sclerosis: a reappraisal after 10 years. Arch Neurol 58:1602-1606

3. Arnett PA, Higginson CI, Voss WD, Bender WI, Wurst JM, Tippin JM (1999) Depression in multiple sclerosis: relationship to working memory capacity. Neuropsychology 13:546-556

4. Arnett PA, Higginson CI, Randolph JJ (2001) Depression in multiple sclerosis: relationship to planning ability. J Int Neuropsychol Soc 7:665-674

5. Assal G (1985) Batterie des examens neuropsychologiques du CHUV. Lausanne

6. Barrash J, Anderson SW, Jones RD, Wefel JS, Tranel D (1997) Iowa scales of personality change: reliability and validity. J Int Neuropsychol Soc 3: 27-28

7. Bechara A, Damasio AR, Damasio H, Anderson SW (1994) Insensitivity to future consequences following damage to human prefrontal cortex. Cognition 50:7-15

8. Bechara A, Damasio H, Damasio AR, Lee GP (1999) Different contributions of the human amygdala and ventromedial prefrontal cortex to decision-making. J Neurosci 19:5473-5481

9. Bechara A, Damasio H, Damasio AR (2000) Emotion, decision making and the orbitofrontal cortex. Cerebr Cortex 10:295-307

10. Bechara A, Damasio AR (2005) The Somatic Marker Hypothesis: a neural theory of economic decision. Games Econ Behav 52:336-372

11. Benedict RH, Fischer JS, Archibald CJ, Arnett PA, Beatty WW, Bobholz J, Chelune GJ, Fisk JD, Langdon DW, Caruso L, Foley F, LaRocca NG, Vowels L, Weinstein A, DeLuca J, Rao SM, Munschauer F (2002) Minimal neuropsychological assessment of MS patients: a consensus approach. Clin Neuropsychol 16:381-397

12. Bolla KI, Eldreth DA, Matochik JA, Cadet JL (2004) Sex-related differences in a Gambling Task and its neurological correlates. Cereb Cortex 14: 1226-1232

13. Bowman $\mathrm{CH}$, Turnbull $\mathrm{OH}$ (2003) Real versus facsimile reinforcers on the Iowa Gambling Task. Brain Cogn 53: 207-210
14. Calabrese P (2006) Neuropsychology of multiple sclerosis. An overview. J Neurol 253(Suppl 1):I/10-I/15

15. Damasio AR (1994) Descartes' Error: Emotion, Reason and the Human Brain. New York: Grosset Putmann

16. Davis C, Patte K, Tweed S, Curtis C (2007) Personality traits associated with decision-making deficits. Personality and Individual Differences 42 : 279-290

17. Ebers CG (2005) Prognostic factors for multiple sclerosis: the importance of natural history studies. J Neurol 252 (Suppl 3):III/15-III/20

18. Ernst M, Paulus MP (2005) Neurobiology of decision making: a selective review from a neurocognitive and clinical perspective. Biol Psychiatry 58:597-604

19. Eslinger PJ, Damasio AR (1985) Severe disturbance of higher cognition after bilateral frontal lobe ablation: patient EVR. Neurology 35:1731-1741

20. Fein G, McGillivray S, Finn P (2007) Older adults make less advantageous decisions than younger adults: cognitive and psychological correlates. J Int Neuropsychol Soc 13:480-489

21. Jenkinson C, Mant J, Carter J, Wade D, Winner S (2000) The London handicap scale: a re-evaluation of its validity using standard scoring and simple summation. J Neurol Neurosurg Psychiatry 68:365-367

22. Kleeberg J, Bruggimann L, Annoni JM, van Melle G, Bogousslavsky J, Schluep M (2004) Altered decision-making capacity in multiple sclerosis: a sign of impaired emotional reactivity? Ann Neurol 56:787-795

23. Kujala P, Portin R, Ruutiainen J (1997) The progress of cognitive decline in multiple sclerosis, a controlled 3-years follow-up. Brain 120:289-297

24. Kurtzke J (1983) Rating neurologic impairment in multiple sclerosis: an expanded disability status scale (EDSS). Neurology 33:1444-1452

25. Landro NI, Celius EG, Sletvold H (2004) Depressive symptoms account for deficient information processing speed but not for impaired working memory in early phase multiple sclerosis (MS). J Neurol Sci 217:211-216

26. Maia TV, McClelland JL (2004) A reexamination of the evidence for the somatic marker hypothesis: What participants really know in the Iowa gambling task. Proc Natl Acad Sci USA 101:16075-16080
27. McDonald WI, Compston A, Edan G, Goodkin D, Hartung HP, Lublin FD, McFarland HF, Paty DW, Polman CH, Reingold SC, Sandberg-Wollheim M, Sibley W, Thompson A, van den Noort S, Weinshenker BY, Wolinsky JS (2001) Recommended diagnostic criteria for multiple sclerosis: guidelines from the international panel on the diagnosis of multiple sclerosis. Ann Neurol 50: 121-127

28. Miller D, Barkhof F, Montalban X, Thompson A, Filippi M (2005) Clinically isolated syndromes suggestive of multiple sclerosis, part 2: non-conventional MRI, recovery processes, and management. Lancet Neurol 4:341-348

29. Mimura M, Oeda R, Kawamura $M$ (2006) Impaired decision-making in Parkinson's disease. Parkinsonism Relat Disord 12:169-175

30. Nagy H, Bencsik K, Rajda C, Benedek K, Beniczky S, Kéri S, Vécsei L (2006) The effects of reward and punishment contingencies on decision making in multiple sclerosis. J Int Neuropsychol Soc 12:559-565

31. Polman CH, Reingold SC, Edan G, Filippi M, Hartung HP, Kappos L, Lublin FD, Metz LM, McFarland HF, O'Connor PW, Sandberg-Wollheim M, Thompson AJ, Weinshenker BG, Wolinsky JS (2005) Diagnostic criteria for multiple sclerosis: 2005 revisions to the "McDonald Criteria". Ann Neurol 58:840-846

32. Rao SM, Leo GJ, Bernardin L, Unverzagt F (1991) Cognitive dysfunction in multiple sclerosis. I. Frequency, patterns, and prediction. Neurology 41 : 685-691

33. Reitan RM, Wolfson D (1985) The Hastead-Reitan Neuropsychological Test Battery: Theory and Clinical Interpretation. Tucson, AZ: Neuropsychology Press

34. Ruggieri RM, Palermo R, Vitello G, Gennuso M, Settipani N, Piccoli F (2003) Cognitive impairment in patients suffering from relapsing-remitting multiple sclerosis with EDSS $\leq 3.5$. Acta Neurol Scand 108:323-326

35. Schwartz JE, Jandorf L, Krupp LB (1993) The measurement of fatigue: a new instrument. J Psychosomat Res 37:753-762

36. Sevy S, Burdick KE, Visweswaraiah H, Abdelmessih S, Lukin M, Yechiam E, Bechara A (2007) Iowa Gambling Task in schizophrenia: A review and new data in patients with schizophrenia and co-occurring cannabis use disorders. Schizophr Res 92:74-84 
37. Simioni S, Ruffieux C, Kleeberg J, Bruggimann L, Annoni JM, Schluep M (2007) Cognition, mood and fatigue in patients in the early stage of multiple sclerosis. Swiss Med Wkly 137:496-501

38. Tavazzi E, Dwyer MG, WeinstockGuttman B, Lema J, Bastianello S, Bergamaschi R, Cosi V, Benedict RH, Munschauer FE 3rd, Zivadinov R (2007) Quantitative diffusion weighted imaging measures in patients with multiple sclerosis. Neuroimage 36 : 746-754
39. Vernay D, Gerbaud L, Biolay S, Coste J, Debourse J, Aufauvre D, Beneton C, Colamarino R, Glanddier PY, Dordain G, Clavelou P (2000) Quality of life and multiple sclerosis: validation of the French version of the MSQOL selfquestionnaire (SEP-59). Rev Neurol 156:247-263
40. Wilson BA, Alderman N, Burgess P, Emslie H, Evans J (1996) Behavioural Assessment of the Dysexecutive Syndrome (BADS) manual. Bury St Edmonds, UK: Thames Valley Test Company

41. Zermatten $A$, Van der Linden $M$, d'Acremont M, Jermann F, Bechara A (2005) Impulsivity and decision making. J Nerv Ment Dis 193:647-650

42. Zigmond AS, Snaith RP (1984) The Hospital Anxiety and Depression Scale. Acta Psychiatr Scand 67:361-370 